\title{
The Reformation and Exploration of the Teaching System of Spring Matriculation Students of the Electronic Information Engineering
}

\author{
Zhongxun Wang, Kangkang Du
}

Institute of Science and Technology for Opto-Electronics Information, Yantai University, Yantai

Shandong 264005, China

Keywords: Spring matriculation; the teaching course system; electronic information

\begin{abstract}
Spring matriculation is an enrollment form opened mainly for graduates from secondary vocational schools. The electronic information engineering about its students' training target is to cultivate special talents with theoretical knowledge, application ability and good practice. At present, the teaching system of traditional electronic information engineering is emphasizing theory and neglecting practice, which bounds development of the spring matriculation students. On the basis of specific investigation and analysis about the theoretical knowledge, application ability and practice of electronic information engineering of the spring matriculation students, the paper explores the reformation about the teaching system.
\end{abstract}

\section{Introduction}

Spring matriculation is an enrollment form opened mainly for graduates from secondary vocational schools. Its aim is to relieve students' stress about the college entrance examination in summer and create more opportunities for students to receive higher education. It is not only good for delaying employment pressure, but also emphasizing the checking about students' comprehensive quality and ability. Meanwhile, spring matriculation provides a chance for colleges to expand their scale of enrollment, and it is helpful to promote reformation about accelerating professional, teaching, management, etc. The electronic information engineering about spring matriculation students' training target is to cultivate special talents. They will have basic theoretical knowledge about electronic technology, communication technology, and intelligent control and signal processing, and application ability, good practice ability. They can also engage in electronic and communication system areas about technological innovation, product research and development, the production management, etc. However, the teaching system of the previous universities emphasizes theory and neglects practice. It is not conform to the status quo that spring matriculation students' poor basic and good practice. Thus, it bounds their development. So it is urgent to reform the teaching system.

\section{The status quo about teaching system of spring matriculation students of the electronic information engineering ${ }^{[1]}$}

The spring matriculation students are mainly from secondary vocational schools. The main cultivation of the students is practicing instead of basic knowledge learning during their high school, which leads to their strong hands-on skills and weak basic theory. Their basic theory is far less than ordinary high school students, especially some basic subjects such as math, English, and some professional subjects such as $\mathrm{C}$ programming language and general physics. The teaching modes of traditional electronic information engineering has obvious deficiency in the aspect of ability cultivation, show that it emphasizes the teaching of theoretical knowledge and neglects the cultivation of practice ability, the theoretical knowledge is also inclined to quality and speed instead of digestion and application, and many of them are lagging behind advanced technology. In the meantime, there are many shortcomings in the traditional practice teaching link, for example, the lack of innovation, the practice in a single form, poor equipment, and excessive dependency theory of teaching, too many verification experiments, single inspection form, and no incentive of innovative thinking, no measurement of hands-on practical ability. To a certain extent, the above 
aspects restrict the development of spring matriculation students. It is imperative to reform the cultivation aspect about teaching of theoretical and hands-on practice ability.

\section{The teaching system reformation of spring matriculation students of electronic information engineering}

\subsection{Adjust the teaching content, updated curriculum theory, reform the inspection way of theoretical knowledge ${ }^{[2]-[3]}$}

The purpose of communicating with corporate management through visiting enterprise is to understand the students' basic commands about theoretical knowledge. We will adjust and select the theoretical teaching content and reduce the difficulty by the enterprise's demand about technical personnel. It demands the purpose of application and the basic requirement of "necessary, enough" that for spring matriculation students' teaching. For spring matriculation students, theoretical basis of high school is poor, especially some public courses such as higher mathematics, ordinary physics. However, these two subjects are needed for electronic information engineering to learn as analysis methods. Besides, it is necessary to supervise and urge students to study in the daily learning. Above all, it is necessary to adjust teaching system, select teaching content, and reduce teaching difficulty. In order to achieve the goal of "necessary, enough", we need to teach basic concept, theory, and methods, and also need to solve practical problems with application. In the final exam, the demands of spring matriculation students are that to get a appropriate change in inspection way of theoretical knowledge, increase the proportion of usually grades, pay more attention to the process. The other ways such as reducing difficulty of the exam appropriately, increasing some topics of openness, having an inspection through open-book, are good methods for students to finish the exam by using the theoretical knowledge.

\section{2 integrate enterprise demand information; revise the practice teaching content, reform the form of practice course inspection}

According to the applied characteristics of spring matriculation education, the training scheme of spring matriculation students need to be revised, the teaching content need to be integrated, the practice teaching link need to be reinforced. To promote the organic combination of theory and practice, the syllabus need to rewrote, and the practice teaching need to be increased in a reasonable range. Meanwhile, it's necessary to reform the content of practice teaching, reduce the number of confirmatory test, increase the independent thinking of students, play a role in a imaginative way. In addition, the enterprise's research projects can be moved into class and be divided into the group .The task can be finished though students' interworking. Theses measures can arouse the enthusiasm of students for learning and guide them to refer to related professional material and also can enhance teamwork cooperative awareness. The form of practice course assessment can be reformed appropriately. For example, students do the different operated subject within the prescribed period of time, which can reduce the possibility of plagiarism and arouse the enthusiasm of learning to a large extent. Also, students can get different grades though the performance in the group, which can arouse the enthusiasm to the practice class.

\subsection{Rely on course contests, efforts to promote teaching system reformation of spring matriculation students}

Electronic information engineering students can attend some discipline competitions of nationwide and the whole province such as electronic design contest, the Internet of things contests. The competitors must possess certain theoretical basic knowledge and strong hands-on practice ability. Otherwise, there isn't any material object but empty ideas. For spring matriculation students, they contact with plenty of practice courses in higher vocational school, for example, PLC technology, circuit welding. These courses are helpful to elevate manipulative ability which can structure students' theoretical knowledge system with the help of electronic discipline competitions of nationwide and whole province. They will get excellent educational effect by combining learning and doing. Simultaneously, some electronic design competitions can be held though allying other enterprises. The requirements including the specialists of enterprise draw up the topic and teach required theoretical knowledge in the scene, and then students contest with each group until 
appraising and electing excellent woks by physical display and argument. The electronic competitions can increase their theoretical knowledge; especially train their practice manipulative ability. At present, the institutes equipped with laboratory about EDA, FPGA and organize students to attend electronic design and the Internet of things competitions all over the nation and province. The students get good performance in all competitions and get national first prize in 2015, which make new breakthrough of the institute's electronic design competitions, and promote the enthusiasm of the learning of theoretical knowledge, meanwhile, exploit the advantages to practice manipulative ability.

\subsection{Establish engineering training centre, exercise students' ability of combining theory and practice}

For the cultivation of spring matriculation students, it's necessary to exploit the advantages of practice manipulative ability, and evade the disadvantages of poor theoretical basis. Spring matriculation students can get involve in the practice by establishing engineering training centre. It will spend 1-2 years in finishing 3-4 entity projects. In order to enhance the spring matriculation students' practice manipulative ability, the following three directions are mentioned:

\subsubsection{Intelligent control direction ${ }^{[4]-[5]}$}

Intelligent control refers to one behavior to control target with advanced intelligent technology, including artificial intelligence and automatic control field, it's the main stage to toward autonomous machine carries out direct self control. The intelligent robot and four rotor aircraft are substantive designs based on intelligent control theory. The Four rotor aircraft's construction divide into four modules: electrical machine module, microcontroller module, sensor module and wireless communication. These modules need to be transferred and reception with sensor, remote sensing device and electrical machine. Intelligent robot equipped with infrared sensor, photoelectric sensor and other circuit, interface. It realizes the function through master chip with certain procedure code. Students can enhance their practice manipulative ability by training intelligent robot and four rotor aircraft in the engineering training centre. Every student can get involve in the research and proceed the field operation in person by the form of grouping. The students can not only learn theoretical knowledge about adapting to the real job demand, but also enhance practice manipulative ability.

\subsubsection{Signal processing direction ${ }^{[6]}$}

Signal processing is a technology to acquire information through processing and recognizing all kinds of information received by computers or other special equipments. The technology can be used to process several of signal, video. At present, the technology adopts typical image acquisition system base on DSP. The gathered image transformed by video chip, and saved in the high-capacity frame memorizer controlled by FPGA, then sent to DSP chip to compressing, finally saved in PC machine and output image. Signal processing can achieve some functions such as strong realize signal, fast transfer, powerful anti-jamming capability in the practical application, which are media device and armamentarium application. In the engineering training centre, the spring matriculation students improve practical manipulative ability by learning and research on processing about video, signal and FPGA algorithm. It's an excellent way to bring the project researched by enterprise to the training centre. Not only can enhance students' practical manipulative ability, but more profit enterprise can acquire, to achieve multi-win.

\subsubsection{Embedded system direction ${ }^{[7]}$}

Embedded system centered with application, which possess the characteristic with highly automated and fast response, especially suitable for dedicated computer system which needs comprehensive strict requirements about instantaneity and multitask. Embedded system constitute with embedded processor, relative support hardware, embedded operating system and application software system including VxWorks, Windows CE, embedded Linux. It's a autonomous working device which applies smart phone operating system such as IOS operating system and android of other phones. The system has wide application field. With the advantage of university-industry cooperation, the engineering training center enhances students' practical manipulative ability; meanwhile, on the background of "Internet+" from nation's advocate, it plays a role in the employment. 
Above all directions promoted the structure of theoretical system and practical manipulative ability. Students can spend 1-2 years finishing 3-4 projects to achieve the combination of theory and practice, and enhance their comprehensive quality.

\section{Implementation effect}

New type teaching system of electronic information engineering is built through reformation of the existing teaching course system. Spring matriculation students not only learn systematic basic theoretical knowledge, but mix practical manipulative ability and overall process of teaching together. Pay attention to the knowledge while to the cultivation of practical manipulative ability. The knowledge teaching, cultivation of ability and creational education are merged so that comprehensive talents cultivated to adapt to the industry development. Just last year, our institute's students of electronic information engineering took an active part in all kinds of science and technology competition and fund program. We got various prize in the electronic design competition of Shandong province, the Internet of things, "challenge cup" university student extracurricular academic science and technology works competition, and succeeded in applying for science and technology fund program.

\section{Conclusion}

The traditional training mode of emphasize theory and neglect practice seriously constraint the development of spring matriculation students of electronic information engineering. According to the students' physical truth, teaching system must exploit the advantage of practical manipulative ability, evade the disadvantage of poor basic theory, regard "necessary, enough" as minimum principle, reduce difficulty of theory exam, increase proportion of practice course, reform form of practice course exam, "have a special treat" to spring matriculation students, exploit the advantage and evade the disadvantage. In order to enhance their comprehensive quality and lay a good foundation to adapt to the work.

\section{References}

[1] Wangang Wang, Jian Yu. Teaching Reform of Higher Vocational Electronic Information Engineering [J]. Changzhou College of information technology, 2009.8(3):20-22 (In Chinese)

[2] Zhongxun Wang, Jianwei Zhao. Electronic Information Science and Technology Practice Teaching System Construction and Research [J]. International Conference on Psychology, Management and Social Science, 2013.01 (In Chinese)

[3] Shiju Sun, Wei Han. Practice Teaching Reform of Higher Vocational Electronic Information Engineering [J]. Innovation in Education, 2010.10(126): 274-275 (In Chinese)

[4] Zixing Cai. Intelligent Control and Mobile Robot Development [J]. Central South University(Natural Sciences), 2005.36(5):723-724 (In Chinese)

[5] Xuan Fang, Bocheng Zhong. Research and Application of four-rotor aircraft[J], Shanghai University of Engineering Science, 2015.29(2):113-114 (In Chinese)

[6] Wei Zhang, Yongwang Wei. Development of digital signal processing and its application in image processing[J]. Science and Technology Information, 2008(29):417 (In Chinese)

[7] Yanzhao Song. Embedded operating system and introduce the principle of selection[J]. Industrial control computer, 2005.18(7) (In Chinese) 